\title{
Observetion of major organs deadaptation change after returning to lower altitude in Qinghai-Tibet railway construction population
}

\author{
Qiquan Zhou ${ }^{1,2^{*}}$, Zhencai Yuan ${ }^{3}$, Xuefeng Zhang ${ }^{4}$, Yahong Zhang ${ }^{3}$, Quansheng Peng ${ }^{3}$, \\ Han Luo ${ }^{1,2}$, Ping Guo ${ }^{1,2}$ \\ ${ }^{1}$ Department of High Altitude Diseases, College of High Altitude Military Medicine, Third Military Medical University, Chongqing, \\ China; ${ }^{*}$ Corresponding Author: zhouqq9918@163.com \\ ${ }^{2}$ Key Laboratory of High Altitude Medicine of Ministry of Education, Key Laboratory of High Altitude Medicine of PLA, Chongq- \\ ing, China \\ ${ }^{3}$ Central Hospital of China Railway First Group Co. Ltd., Xianyang, China \\ ${ }^{4}$ Golmud City People’s Hospital, Golmud, China
}

Received 15 November 2013; revised 17 December 2013; accepted 25 January 2014

Copyright (C) 2014 Qiquan Zhou et al. This is an open access article distributed under the Creative Commons Attribution License, which permits unrestricted use, distribution, and reproduction in any medium, provided the original work is properly cited. In accordance of the Creative Commons Attribution License all Copyrights @ 2014 are reserved for SCIRP and the owner of the intellectual property Qiquan Zhou et al. All Copyright (C) 2014 are guarded by law and by SCIRP as a guardian.

\section{ABSTRACT}

High altitude deadaptation affects the health of population returned to the plain. We examined major physiological functions in $\mathbf{3 4 8}$ healthy control subjects and 626 Qinghai-Tibet railway construction workers who returned to the plain from the Qinghai-Tibet plateau. Blood indices, such as hemoglobin, hematocrit, mean corpuscular volume, mean corpuscular hemoglobin concentration and platelet larger cell ratio, of the returned group that had stayed at high altitude more than $\mathbf{3}$ years were significantly higher than those of the control group. Red blood cell distribution width and platelet were significantly lower in the returned group than in the control group. Compared to the control group, five years after returning to the plain, the returned group had higher mean corpuscular hemoglobin and lower red blood cell distribution width. Detection rate of hypotension and low pulse pressure were significantly higher in the returned group than in the control group at 20 months after the return, and cardiothoracic ratio was significantly higher in the returned group than in the control group at $\mathbf{4 0}$ months after the return. Short-term memory function was significantly lower in the returned group than in the control group. Total triiodothyronine and thyroid-stimulating hormone were significantly lower, but total thyroxine and free triiodothyronine were significantly higher in the returned group than in the control group. Sex hormones level returned to normal level in the returned group. Superoxide dismutase was significantly higher and malondialdehyde was significantly lower in the returned group than in the control group. Fatty acid binding protein was significantly higher in the returned group than in the control group, and this difference maintained with time after the return. We conclude that physiological functions of most organs in returned population after exposed to high altitude can not be completely restored to the normal level in a short period of time.

\section{KEYWORDS}

Deadaptation; Blood Indexes; Cycle Indicators; Oxygen Free Radicals; Thyroid Function; Sex Hormones

\section{INTRODUCTION}

High altitude deadaptation is also called "oxygen intoxication syndrome”. After plain residents live at high altitude for a period time, their bodies undergo a series of functional and structural changes to adapt to high altitude; when they then return to the plain, the adaptive changes acquired under the hypoxia environment at high altitude must be readjusted to readapt to low altitude environment. The clinical syndrome that occurs during this 
process is called high altitude deadaptation [1,2]. In the past due to lack of understanding of high altitude deadaptation, researches on its pathogenic mechanism were also rare, further hindering our understanding of this syndrome for a long time. This to some extent not only hampers proper care for the physical and mental health of people who return from high altitude to the plain, but also affects their work efficiency after the return; in some severe cases, it may also affect their health [3-5].

It remains unclear when people return from high altitude to the plain whether they can quickly recover from the damages caused by hypoxia, or whether these damages become aggravated, or whether other adverse responses occur. Therefore, to investigate in depth the deadaptation of the physiological functions in people who are exposed to high altitude upon their return to low altitude helps to thoroughly solve the medical problems. Meanwhile, currently there is neither clear regulation nor theoretical basis as to how long high altitude construction workers should wait in the plain after their return before they can go back to the high altitude for more work; in most cases, such decisions are made based on an as-needed basis. To solve this problem, both theoretical and practical perspectives are essential as the development and construction of high altitude areas are growing faster and faster today. Thus to study the deadaptation of different physiological functions in plateau railway construction workers upon their return to the plain and to provide theoretical basis for the medical care for this population are of important theoretical and practical significance.

\section{SUBJECTS AND METHODS}

\subsection{Subject Selection}

The observation group was composed of 626 workers who participated in the second phase project of QinghaiTibet railway construction with an accumulative work time of over 6 months and have returned to the plain, including 574 males and 52 female, with an age range of 24 - 61 years old and a mean age of 36.56 years old; the altitudes of the constructions sites ranged 3080 - $5072 \mathrm{~m}$, and the mean was $4073.98 \mathrm{~m}$; time spent in high altitude construction ranged 6 - 60 months and the mean was 30.61 months; time spent in the plain after returning ranged 19 - 66 months, and the mean was 32.47 months. During the whole time of high altitude construction, necessary facilities to improve living conditions including heating and oxygen supply equipments were provided according to related regulations of the ministry of railways. Aside from a small number of management staff, all other subjects included in the observation group were front line construction workers. The control group was composed of 348 subjects who had never participated in the Qinghai-Tibet railway construction and were longterm residents in the plains, who were certified as healthy via physical examination by standard hospitals in recent years, and whose job natures, labor intensities and ages roughly matched those of subjects in the observation group (305 males, 43 females, 19 - 65 years old, mean 36.53 years old). In order to remove the influence of gender imbalance on the statistical results, only data collected from male workers were included in the analysis. This study was approved by the medical ethical committee of the Central Hospital of China Railway First Group Co. Ltd. and the Third Military Medical University. All subjects gave their informed consent in writing.

\subsection{Observation Indices}

1) Hematological parameters: these included RBC, HGB, HCT, MCV, MCH, MCHC, RDW, PLT, PDW, MPV, P-LCR, white blood cell count (WBC), lymphocyte percentage (LYM\%), neutrophils percentage (NEUT\%), absolute lymphocyte count (LYM\#) and absolute neutrophils count (NEUT\#).

2) Indices of the circulation function: these mainly included blood pressure (systolic and diastolic pressures), pulse pressure, cardiothoracic ratio (CTR) and EKG.

3) Indices related to short-term memory: these were measured by delayed oral word memory test, short-term (numbers) recall test and keyboard operation test.

4) Indices of thyroid function: these included TT3, TT4, FT3, FT4 and TSH.

5) Indices of sex hormone: these included FSH, LH, PRL, progesterone, testosterone and $\mathrm{E}_{2}$.

6) Indices related to free radicals: these include human ROS, SOD, MDA, GSH-PX, NOS and NO.

7) Indices for neural damages: these included human MBP, human S100 and human NSE.

8) Indices related to immunology: these included human immunoglobulins A/G/M (IgA, IgG, IgM) and TRF.

\subsection{Test Methods}

Hematological tests: vacuum EDTA-K2 anticoagulant blood collection tube was used to collect $2 \mathrm{ml}$ fasting blood from the ulnar vein in the morning; Sysmex kx-21 automated hematology analyzer (Sysmex Corp., Japan) and specialized agents provided by Shandong Lanqiao Medical Science and Technology Ltd. (China) were employed for the tests.

Tests for circulation functions: All blood pressure measurements were performed using mercury sphygmomanometer manufactured by Shanghai Medical Instrument Company, Medical Equipment Factory; the right upper arm blood pressure in the sitting position was measured after the subject had been in quiet rest for 10 min. Blood pressure evaluation criteria: systolic pressure 
$\geq 140 \mathrm{mmHg}$ and diastolic pressure $\geq 90 \mathrm{mmHg}$ were considered the criteria for high blood pressure; systolic pressure $<100 \mathrm{mmHg}$ and diastolic pressure $<60 \mathrm{mmHg}$ were considered the criteria for low blood pressure; pulse pressure $>40 \mathrm{mmHg}$ was considered the criterion for high pulse pressure and $<30 \mathrm{mmHg}$ for low pulse pressure. Cardiothoracic ratio was measured using JF10 portable X-ray machine manufactured by Qingdao Zhonglian Hainuo Medical Science and Technology Ltd. (China); CTR = cardiac transverse diameter/transverse diameter of the thoracic cage. ECG-6511 electrocardiograph machine manufactured by Shanghai Kohden Medical Electronic Instrument Corporation (China) was used for routine electrocardiogram.

Tests for short-term memory: these included delayed oral word memory test, short-term recall test and keyboard operation test. The delayed oral recall test: special word memory cards were made based on the delayed oral recall test principle proposed by Dr. Mary Tierney from Sunnybrook Health Science Center, and used for the test [6]; the test score was the number of words that could be correctly repeated; the test was performed two times and the higher score was used as the final test score. The short-term recall test: special software was designed to mimic brain age test games for the short-term recall test; the test was performed two times and the lower score was used as the final test score. Keyboard operation: self-designed test software was used; score was based on the length of numerical numbers correctly input at a time; the test was performed two times and the higher score was used as the final test score.

Tests for thyroid function: $\mathrm{TT}_{3}, \mathrm{TT}_{4}, \mathrm{FT}_{3}, \mathrm{FT}_{4}$ and TSH were measured with chemiluminescence method; JETLIA-962 chemiluminescence immunassay analyzer and the specialized reagent kit provided by Beijing Yuande Biomedical Engineering Ltd. (China) were used.

Tests for sex hormones: serum FSH, LH, PRL, progesterone, testosterone and $\mathrm{E}_{2}$ levels were measured with chemiluminescence method; JETLIA-962 chemiluminescence immunassay analyzer and the reagent kit provided by Beijing Yuande Biomedical Engineering Ltd. (China) were used.

Tests for free radical related indices: serum ROS activity level was measured using doulbe antibody sandwich enzyme-linked immunosorbent assay (DAS-ELISA); test agents used were ROS reagent kit manufactured by RND company (USA) and packed by Shanghai Langdun Biotech Ltd. (China). SOD, MDA, GSH-PX, NOS, NO levels were measured using XD-811 semi automatic biochemistry analyzer manufactured by Shanghai Tongda Medical Instrument Corp. (China); test reagent kit was provided by Changchun Huili Biotech Ltd. (China).

Tests for neural damage indices: serum MBP, S100 and NSE contents were measured using DAS-ELISA; Mairui BS-300 automated biochemistry analyzer manufactured by Shanghai Fuzhong Bioscience Ltd. (China) was used; the test reagent kit was manufactured by RND company (USA) and packed by Shanghai Langdun Biotech Ltd. (China).

Tests for immunological indices: serum IgA, IgG, IgM and TRF levels were measured using the immunoturbidity method. Mairui BS-300 automated biochemistry analyzer manufactured by Shanghai Fuzhong Bioscience Ltd. (China) was used; the test reagent kit was provided by Shanghai Jiemen Biotech Corporation (China).

\subsection{Statistical Analysis}

Data analyses were performed using SPSS 16.0 statistics software and the results were presented as mean \pm standard deviation. To compare two sample groups, $t$-test for two independent samples was used; chi-square test was performed to compare ratios; partial correlation analysis was used to estimate the linear correlation between variables.

\section{RESULTS}

\subsection{Changes in Hematological Indices after Returning to Low Altitude}

\section{Early Stage Changes}

Red blood cell system: There were no statistically significant between-group differences in red blood cell (RBC) and mean corpuscular hemoglobin concentration (MCHC) $(p>0.05)$; hemoglobin (HGB), hematocrit (HCT), mean corpuscular volume (MCV) and mean corpuscular hemoglobin $(\mathrm{MCH})$ of the observation group were all significantly higher that those of the control group, and red blood cell distribution width (RDW) of the observation group was significantly lower than that of the control group $(p<0.01)$. See Table 1 .

Table 1. RBC, HGB, HCT, MCV, MCH, MCHC and RDW of Qinghai-Tibet plateau construction workers at an early stage after returning to the plain $(\bar{x} \pm s)$.

\begin{tabular}{ccccccccc}
\hline Group & $n$ & RBC $\left(\times 10^{12} / \mathrm{L}\right)$ & HGB $(\mathrm{g} / \mathrm{L})$ & MCH $(\%)$ & MCV (fL) & MCH (pg) & MCHC (g/L) & RDW (CV) \\
\hline Control group & 348 & $4.96 \pm 0.50$ & $149 \pm 11.5$ & $0.45 \pm 0.05$ & $90.3 \pm 6.9$ & $30.3 \pm 4.2$ & $336 \pm 46$ & $13.0 \pm 1.7$ \\
Observation group & 626 & $4.98 \pm 0.53$ & $155 \pm 14.2^{\mathrm{b}}$ & $0.46 \pm 0.05^{\mathrm{a}}$ & $92.4 \pm 6.4^{\mathrm{b}}$ & $31.4 \pm 3.5^{\mathrm{b}}$ & $341 \pm 46$ & $11.7 \pm 3.0^{\mathrm{b}}$ \\
\hline
\end{tabular}

Note: Compared with the control group, ${ }^{\mathrm{a}} p<0.05$, ${ }^{\mathrm{b}} p<0.01$. 
Correlation analysis showed that after control for factors including body mass index (BMI), blood pressure and age, HGB, HCT and MCV were positively correlated with the altitude of the construction site and the residence time at high altitude; also HGB, HCT and MCV were Negatively correlated with the time after returning to low altitude. RDW showed the opposite trend, it was negatively correlated with the altitude of the construction site and the residence time at high altitude,yet positively correlated with the time after returning to low altitude. MCH was positively correlated with the residence time at high altitude. RBC was positively correlated with the altitude of the construction site.

Platelet system: There were no significant betweengroup differences in platelet distribution width (PDW) and mean platelet volume (MPV) $(p>0.05)$; PLT of the observation group was significantly lower than that of the control group; platelet larger cell ratio (P-LCR) of the observation group was significantly higher than that of the control group $(p<0.01)$. See Table 2 . Correlation analysis showed that after control for age and BMI, PLT was negatively correlated with the altitude of the construction site and the residence time at high altitude, yet positively correlated with the time after returning to low altitude. P-LCR was positively correlated with the altitude of the construction site and the residence time at high altitude, yet negatively correlated with the time after returning to low altitude.

Based on the above results, HGB, HCT, MCV, MCH, MCH and P-LCR higher than normal levels and PLT lower than normal level were statistically analyzed. The results showed that HGB, HCT, MCH and P-LCR of the observation group were significantly different from those of the control group ( $p<0.01$ or $p<0.05$ ). Further correlation analysis showed that after control for age and BMI, the detection rates of HGB, MCT, MCH and P-LCR higher than normal were positively correlated with altitude of the construction site and the residence time at high altitude, yet negatively correlated with the time after returning to low altitude. The detection rate of platelet (PLT) lower than normal was not significantly correlated with any of the above factors. The indices of the granulocyte system of the observation group were not significantly different from those of the control group ( $p>$ 0.05).

\subsection{Changes in Hematological Indices 5 Years after Returning to Low Altitude}

Follow-up studies were performed on 135 subjects in the observation group (130 males, 5 females; age 27 - 61 years old, mean 37.98 years old; altitude of construction site 3080 - $5231 \mathrm{~m}$, mean $4014.8 \mathrm{~m}$; mean residence time at high altitude 33.61 months) five years after returning to the plain. The results showed that MCHC of the ob-
Table 2. PLT, PDW, MPV, and P-LCR of Qinghai-Tibet plateau construction workers at an early stage after returning to the plain $(\bar{x} \pm s)$.

\begin{tabular}{cccccc}
\hline Group & $n$ & PLT $\left(\times 10^{9} / \mathrm{L}\right)$ & PDW (\%) & MPV (fl) & P-LCR (\%) \\
\hline $\begin{array}{c}\text { Observation } \\
\text { group }\end{array}$ & 626 & $180 \pm 57^{\mathrm{b}}$ & $15.0 \pm 3.35$ & $10.6 \pm 2.1$ & $0.31 \pm 0.13^{\mathrm{b}}$ \\
$\begin{array}{c}\text { Control group } \\
348\end{array}$ & $203 \pm 59$ & $14.9 \pm 2.51$ & $10.5 \pm 1.4$ & $0.27 \pm 0.08$ \\
\hline
\end{tabular}

Note: Compared with the control group, ${ }^{\mathrm{b}} p<0.01$.

servation group was significantly higher than that of the control group, and the mean RDW of the observation group was significantly lower than that of the control group; there were no significant differences in all other indices between the two groups (Table 3). For the platelet system, there were no significant differences in all indices between the two groups (Table 4).

Thus it can be seen that hematology is a sensitive index for high altitude deadaptation. Persistently abnormal hematological indices after descending from high altitude are important indicators of high altitude deadaptation symptoms; it takes about 5 years for the hematological indices of population exposed to high altitude restore to control level after returning to the plain.

\subsection{Changes in Blood Pressure and Pulse Pressure after Returning to Low Altitude}

When comparing Qinghai-Tibet railway construction workers in the observation group during deadaptation after their return to the plain with subjects in the control group, there were no significant differences in systolic pressure, diastolic pressure or pulse pressure between the groups (Table 5). After grouping construction workers by residence time at high altitude ( $>40$ months, $21-40$ months and $\leq 20$ months), by altitude of construction site (3000 m, $3751 \mathrm{~m},>4500 \mathrm{~m}$ ), and by time after returning to the plain ( $\leq 20$ months, 21 - 40 months, $>40$ months), aside from the subgroup with time after returning to the plain $\leq 20$ months, whose diastolic pressure was significantly lower than that of the control $(74.92 \pm 12.51$ vs $77.60 \pm 10.08 \mathrm{mmHg}, p<0.05)$, there were no significant differences in systolic pressure, diastolic pressure or pulse pressure between all other subgroups and the control.

The low blood pressure detection rate in the observation group was significantly higher than that of the control group; there were no significant differences in the detection rates of high blood pressure, low pulse pressure or high pulse pressure between the groups (Table 6). After grouping construction workers by time after returning to the plain ( $\leq 20$ months, $21-40$ months, $>40$ months), by residence time at high altitude ( $>40$ months, 
Table 3. RBC, HGB, HCT, MCV, MCH, MCHC and RDW of Qinghai-Tibet plateau construction workers five years after returning to the plain $(\bar{x} \pm s)$.

\begin{tabular}{|c|c|c|c|c|c|c|c|c|}
\hline Group & $n$ & $\mathrm{RBC} \quad\left(\times 10^{12} / \mathrm{L}\right)$ & HGB $\quad(g / L)$ & MCH (\%) & MCV (fL) & MCH (pg) & MCHC $\quad(g / L)$ & RDW (CV) \\
\hline Observation group & 135 & $5.13 \pm 0.33$ & $156.7 \pm 10.9$ & $46.38 \pm 3.04$ & $89.74 \pm 8.90$ & $30.59 \pm 1.54$ & $338 \pm 17.2^{\mathrm{b}}$ & $43.45 \pm 4.27^{\mathrm{a}}$ \\
\hline Control group & 184 & $5.05 \pm 0.55$ & $154.4 \pm 12.5$ & $47.05 \pm 4.20$ & $91.98 \pm 10.3$ & $30.7 \pm 2.19$ & $328 \pm 17.9$ & $45.58 \pm 4.86$ \\
\hline
\end{tabular}

Note: Compared with the control group, ${ }^{\mathrm{a}} p<0.05,{ }^{\mathrm{b}} p<0.01$.

Table 4. PLT, PDW, MPV, and P-LCR of Qinghai-Tibet plateau construction workers five years after returning to the plain $(\bar{x} \pm s)$.

\begin{tabular}{|c|c|c|c|c|c|}
\hline Group & $n$ & $\operatorname{PLT}\left(\times 10^{9} / \mathrm{L}\right)$ & PDW (\%) & MPV (fl) & P-LCR (\%) \\
\hline $\begin{array}{l}\text { Observation } \\
\text { group }\end{array}$ & 135 & $177 \pm 55.0^{\mathrm{a}}$ & $15.2 \pm 2.80^{\mathrm{a}}$ & $11.7 \pm 1.09^{\mathrm{a}}$ & $38.5 \pm 8.30^{\mathrm{a}}$ \\
\hline Control group & 184 & $164 \pm 53.7$ & $16.2 \pm 5.32$ & $11.5 \pm 1.11$ & $37.4 \pm 8.45$ \\
\hline
\end{tabular}

Note: Compared with the control group, ${ }^{\mathrm{a}} p<0.05$.

Table 5. Blood pressure of Qinghai-Tibet plateau construction workers after returning to the plain $(\bar{x} \pm s)$.

\begin{tabular}{ccccc}
\hline Group & $n$ & $\begin{array}{c}\text { Systolic pressure } \\
(\mathrm{mmHg})\end{array}$ & $\begin{array}{c}\text { Systolic pressure } \\
(\mathrm{mmHg})\end{array}$ & $\begin{array}{c}\text { Pulse pressure } \\
(\mathrm{mmHg})\end{array}$ \\
\hline $\begin{array}{c}\text { Observation } \\
\text { group }\end{array}$ & 626 & $117.49 \pm 12.97^{\mathrm{a}}$ & $77.57 \pm 10.68^{\mathrm{a}}$ & $39.91 \pm 8.34^{\mathrm{a}}$ \\
$\begin{array}{c}\text { Control } \\
\text { group }\end{array}$ & 348 & $118.64 \pm 13.29$ & $78.91 \pm 9.49$ & $39.76 \pm 7.92$ \\
\hline
\end{tabular}

Note: Compared with the control group, ${ }^{\mathrm{a}} p<0.05$.

Table 6. Blood and pulse pressure of Qinghai-Tibet plateau construction workers at different time after returning to the plain.

\begin{tabular}{ccccc}
\hline Group & $\begin{array}{c}\text { High blood } \\
\text { pressure }\end{array}$ & $\begin{array}{c}\text { Low blood } \\
\text { pressure }\end{array}$ & $\begin{array}{c}\text { High pulse } \\
\text { pressure }\end{array}$ & $\begin{array}{c}\text { Low pulse } \\
\text { pressure }\end{array}$ \\
\hline$\leq 20$ months & $15 / 99$ & $14 / 99^{\mathrm{b}}$ & $34 / 99$ & $7 / 99$ \\
21 - 40 months & $54 / 431$ & $23 / 431$ & $125 / 431$ & $25 / 431$ \\
$>40$ months & $14 / 96$ & $3 / 96^{\mathrm{a}}$ & $33 / 96$ & $5 / 96$ \\
Control group & $41 / 348$ & $7 / 348$ & $74 / 348$ & $8 / 348$ \\
\hline
\end{tabular}

Note: Compared with the control group, ${ }^{\mathrm{a}} p<0.05,{ }^{\mathrm{b}} p<0.01$.

21 - 40 months and $\leq 20$ months), and by altitude of construction site $(3000 \mathrm{~m}, 3751 \mathrm{~m},>4500 \mathrm{~m})$, the detection rate of low blood pressure of the subgroup with time after returning to the plain $\leq 20$ months was significantly higher than that of the control group $(p<0.01)$; the detection rates of low blood pressure of the subgroups with residence time at high altitude 21 - 40 months and $\leq 20$ months were significantly higher than that of the control group, whereas the detection rate of low pulse pressure of the subgroup with residence time at high altitude $>40$ months were significantly higher than that of the control group ( $p<0.05$ ); the detection rate of low blood pressure of the subgroup with altitude $>4500 \mathrm{~m}$ was significantly higher than that of the control group, whereas the detection rate of low pulse pressure of the subgroup with altitude $\sim 3751 \mathrm{~m}$ was significantly higher than that of the control group $(p<0.05)$. There were no significant differences between the other subgroups and the control group (Table 6).

Correlation analysis showed that after control for age, systolic pressure was negatively correlated with the altitude of the construction site $(r=-0.084, p=0.025)$, and positively correlated with the time after returning to the plain $(r=0.081, p=0.032)$; the diastolic pressure was positively correlated with the time after returning to the plain $(r=0.089, p=0.018)$; the detection rate of low blood pressure was positively correlated with the altitude of the construction site $(r=-0.121, p=0.001)$; the detection rate of low pulse pressure was positively correlated with the altitude of construction site and the residence time at high altitude $(r=-0.100, p=0.008)$ (Tables 7 and 8). As the time of construction work at high altitude or the altitude of the construction site increased, the low blood pressure and low pulse pressure at high altitude tended to increase.

\subsection{Changes in Cardiothoracic Ratio after Returning to Low Altitude}

The test results showed that cardiothoracic ratio (CTR) of population exposed to high altitude was $0.498 \pm 0.023$, which was significantly high than that of the control group $0.494 \pm 0.017(p<0.05)$. After grouping construction workers by residence time at high altitude $(>40$ months, $21-40$ months and $\leq 20$ months) and by time after returning to the plain ( $\leq 20$ months, 21 - 40 months, $>40$ months), the CTR of the subgroup with residence time at high altitude $>40$ months was significantly higher than that of the control group $(p<0.05)$; after grouping construction workers by altitude of construction site $(3000 \mathrm{~m}, 3751 \mathrm{~m},>4500 \mathrm{~m})$, there were significant differences in CRT between the $3000 \mathrm{~m}$ or the $3751 \mathrm{~m}$ subgroup and the control group $(p<0.05)$ (Tables 9-11). 
Table 7. Blood and pulse pressure of Qinghai-Tibet plateau construction workers with different residence time at high altitude.

\begin{tabular}{ccccc}
\hline Group & $\begin{array}{c}\text { High blood } \\
\text { pressure }\end{array}$ & $\begin{array}{c}\text { Low blood } \\
\text { pressure }\end{array}$ & $\begin{array}{c}\text { High pulse } \\
\text { pressure }\end{array}$ & $\begin{array}{c}\text { Low pulse } \\
\text { pressure }\end{array}$ \\
\hline$>40$ months & $28 / 164$ & $9 / 164$ & $58 / 164$ & $16 / 164^{\mathrm{a}}$ \\
21 - 40 months & $35 / 279$ & $17 / 279^{\mathrm{a}}$ & $87 / 279$ & $13 / 279$ \\
$\leq 20$ months & $22 / 183$ & $12 / 183^{\mathrm{a}}$ & $57 / 183$ & $8 / 183$ \\
Control group & $41 / 348$ & $7 / 348$ & $74 / 348$ & $8 / 348$ \\
\hline
\end{tabular}

Note: Compared with the control group, ${ }^{\mathrm{a}} p<0.05$.

Table 8. Blood and pulse pressure of Qinghai-Tibet plateau construction workers at different altitudes.

\begin{tabular}{ccccc}
\hline Group & $\begin{array}{c}\text { High blood } \\
\text { pressure }\end{array}$ & $\begin{array}{c}\text { Low blood } \\
\text { pressure }\end{array}$ & $\begin{array}{c}\text { High pulse } \\
\text { pressure }\end{array}$ & $\begin{array}{c}\text { Low pulse } \\
\text { pressure }\end{array}$ \\
\hline$>4500 \mathrm{~m}$ & $35 / 238$ & $17 / 238^{\mathrm{a}}$ & $66 / 238$ & $13 / 238$ \\
$3751 \mathrm{~m} \sim$ & $16 / 146$ & $10 / 146$ & $44 / 146$ & $14 / 146^{\mathrm{a}}$ \\
$3000 \mathrm{~m} \sim$ & $42 / 242$ & $11 / 242$ & $91 / 242$ & $9 / 242$ \\
Control group & $41 / 348$ & $7 / 348$ & $74 / 348$ & $8 / 348$ \\
\hline
\end{tabular}

Note: Compared with the control group, ${ }^{\mathrm{a}} \mathrm{p}<0.05$.

Table 9. Cardiothoracic ratio of Qinghai-Tibet plateau construction workers with different residence time at high altitude.

\begin{tabular}{ccc}
\hline Group & Number of cases & CTR $(\bar{x}+s)$ \\
\hline$>40$ months & 164 & $0.504 \pm 0.027^{\mathrm{a}}$ \\
21 - 40 months & 279 & $0.495 \pm 0.018$ \\
$\leq 20$ months & 183 & $0.496 \pm 0.023$ \\
Control group & 348 & $0.494 \pm 0.018$ \\
\hline
\end{tabular}

Note: Compared with the control group, ${ }^{\mathrm{a}} p<0.05$.

Table 10. Test results on cardiothoracic ratio of Qinghai-Tibet plateau construction workers at different time after returning to plain.

\begin{tabular}{ccc}
\hline Group & Number of cases & $\operatorname{CTR}(\bar{x}+s)$ \\
\hline$>40$ months & 96 & $0.499 \pm 0.024^{\mathrm{a}}$ \\
$21-40$ months & 431 & $0.498 \pm 0.023^{\mathrm{a}}$ \\
$\leq 20$ months & 99 & $0.496 \pm 0.022$ \\
Control group & 348 & $0.494 \pm 0.018$ \\
\hline
\end{tabular}

Note: Compared with the control group, ${ }^{\mathrm{a}} p<0.05$.

Correlation analysis showed that after controlling for age and BMI, CTR was positively correlated with residence time at high altitude $(r=0.167, p=0.000)$, negatively correlated with the time after returning to the plain $(r=-0.137, p=0.001)$, and not significantly correlated with altitude of construction site ( $r=0.061, p=0.145)$. Thus it can be seen that the cardiomorphological changes caused by high altitude exposure is correlated with the time of exposure to high altitude, and not correlated with the time after returning to the plain; 3 years after returning to the plain, cardiomorphology still cannot restore to control normal.

\subsection{Memory and Operation Functions after Returning to Low Altitude}

Test results from subjects who had returned to the plain from high altitude for more than 3 years showed that the scores in the delayed oral memory test and the keyboard operation test of the observation group were slightly higher than those of the control group, and the score in the short-term recall test was slight lower than that of the control group, but the differences were not significant in all cases (Table 12). Correlation analysis showed that after control for age, sex and degree of education, scores in the delayed oral memory test, the shortterm recall test or the keyboard operation test were not significantly correlated with altitude of construction site, residence time at high altitude or time after returning to the plain. After control for altitude of construction site, residence time at high altitude and time after returning to the plain, scores in the delayed oral memory test and the keyboard operation test were both positively correlated with degree of education, and negatively correlated with age; score in the short-term recall test was positively correlated with age, and negatively correlated with degree of education. That three indices are not correlated with alti-

Table 11. Test results on cardiothoracic ratio of Qinghai-Tibet plateau construction workers at different altitudes.

\begin{tabular}{ccc}
\hline Group & Number of cases & $\operatorname{CTR}(\bar{x}+s)$ \\
\hline $35500 \mathrm{~m}$ & 238 & $0.496 \pm 0.023$ \\
$3051 \mathrm{~m} \sim$ & 146 & $0.499 \pm 0.024^{\mathrm{a}}$ \\
Control group & 242 & $0.498 \pm 0.023^{\mathrm{a}}$ \\
\hline
\end{tabular}

Note: Compared with the control group, ${ }^{\mathrm{a}} p<0.05$.

Table 12. Scores in the delayed oral memory test, short-term recall test and keyboard operation test of of plateau construction workers after returning to plain $(\bar{x} \pm s)$.

\begin{tabular}{ccccc}
\hline Group & $n$ & $\begin{array}{c}\text { Delayed oral } \\
\text { memory test }\end{array}$ & $\begin{array}{c}\text { Short-term } \\
\text { recall test }\end{array}$ & $\begin{array}{c}\text { Keyboard } \\
\text { operation }\end{array}$ \\
\hline Observation group & 132 & $9.13 \pm 2.83^{\mathrm{a}}$ & $30.08 \pm 7.56^{\mathrm{a}}$ & $24.76 \pm 7.57^{\mathrm{a}}$ \\
Control group & 178 & $8.74 \pm 2.98$ & $31.68 \pm 10.83$ & $24.00 \pm 7.72$ \\
\hline
\end{tabular}

Note: Compared with the control group, ${ }^{a} p<0.05$. 
tude, residence time at high altitude or time after returning to the plain suggests that 3 years after returning to the plain, the speed of sensory-motor functions and visual perception/memory of population exposed to high altitude have mostly restored to the control level of plain population of the same age.

\subsection{Changes in Thyroid Function after Returning to Low Altitude}

The $\mathrm{TT}_{3}$ and thyroid-stimulating hoemone (TSH) levels of the observation group were lower than those of the control group, but the differences were not significant; the total thyroxine $\left(\mathrm{TT}_{4}\right)$ and free triiodothyronine $\left(\mathrm{FT}_{3}\right)$ levels of the observation group were significantly higher than those of the control group ( $p<0.01$ ) (Table 13). To further analyze the influences of construction altitude, residence time at high altitude and time after returning to the plain, the construction workers were grouped by altitude of construction site (3000 m, $3751 \mathrm{~m},>4500 \mathrm{~m}$ ), by residence time at high altitude ( $>40$ months, 21 - 40 months and $\leq 20$ months), and by time after returning to the plain ( $\leq 20$ months, 21 - 40 months, $>40$ months), and different subgroups were compared with the control group. The results showed that $\mathrm{TT}_{4}, \mathrm{FT}_{3}$ and free thyroxine $\left(\mathrm{FT}_{4}\right)$ levels tended to increase as the construction altitude and residence time at high altitude increased, and tended to be close to the control value as the time after returning to the plain increased; $\mathrm{TT}_{3}$ and $\mathrm{TSH}$ levels showed the opposite trend, tending to decrease as the construction altitude and residence time at high altitude increased, and approaching the control value as the time after returning to the plain increased (Tables 13-16).

Correlation analysis showed that after control for age, $\mathrm{TT}_{3}$ level was negatively correlated with construction altitude and residence time at high altitude; $\mathrm{TT}_{4}$ and $\mathrm{FT}_{3}$ levels were positively correlated with residence time at high altitude; $\mathrm{FT}_{4}$ level was positively correlated with construction altitude and residence time at high altitude.

It thus can be seen that thyroid function is in a highly active state in population chronically exposed to hypoxia environment at high altitude, and the degree is correlated with both the altitude and time of exposure; after returning to the plain it gradually decreases toward the level of plain control group, but has not completely reached the normal level within the time range of this investigation; it needs more time to restore to the level of healthy plain residents.

Table 13. Test results on TT3, TT4, FT3, FT4 and TSH levels during the deadaptation of populations after returning to plain exposed to high altitude $(\bar{x} \pm s)$.

\begin{tabular}{ccccccc}
\hline Group & $n$ & $\mathrm{TT}_{3}(\mu \mathrm{g} / \mathrm{L})$ & $\mathrm{TT}_{4}(\mu \mathrm{g} / \mathrm{L})$ & $\mathrm{FT}_{3}(\mathrm{pmol} / \mathrm{L})$ & $\mathrm{FT}_{4}(\mathrm{pmol} / \mathrm{L})$ & $\mathrm{TSH}(\mathrm{mIU} / \mathrm{L})$ \\
\hline Observation group & 626 & $1.563 \pm 1.022$ & $72.445 \pm 25.313^{\mathrm{b}}$ & $6.986 \pm 3.341^{\mathrm{b}}$ & $11.674 \pm 1.452^{\mathrm{a}}$ & $1.662 \pm 1.363$ \\
Control group & 348 & $1.716 \pm 1.295$ & $69.746 \pm 26.774$ & $5.051 \pm 3.786$ & $10.578 \pm 1.767$ & $1.813 \pm 1.315$ \\
\hline
\end{tabular}

Note: Compared with the control group, ${ }^{\mathrm{a}} p<0.05,{ }^{\mathrm{b}} p<0.01$.

Table 14. Test results on TT3, TT4, FT3, FT4 and TSH levels of populations exposed to different altitudes $(\bar{x} \pm s)$.

\begin{tabular}{|c|c|c|c|c|c|c|}
\hline Group & $n$ & $\mathrm{TT}_{3}(\mu \mathrm{g} / \mathrm{L})$ & $\mathrm{TT}_{4}(\mu \mathrm{g} / \mathrm{L})$ & $\mathrm{FT}_{3}(\mathrm{pmol} / \mathrm{L})$ & $\mathrm{FT}_{4}(\mathrm{pmol} / \mathrm{L})$ & TSH (mIU/L) \\
\hline Control group & 348 & $1.744 \pm 1.444$ & $60.56 \pm 25.29$ & $5.056 \pm 3.227$ & $10.69 \pm 7.193$ & $1.801 \pm 1.318$ \\
\hline $3000 \mathrm{~m}$ & 242 & $1.657 \pm 0.983$ & $70.86 \pm 27.34^{\mathrm{b}}$ & $7.059 \pm 3.464^{b}$ & $11.99 \pm 7.675$ & $1.646 \pm 1.358$ \\
\hline $3751 \mathrm{~m}$ & 146 & $1.339 \pm 0.758^{\mathrm{b}}$ & $67.73 \pm 24.93^{\mathrm{a}}$ & $6.899 \pm 3.477^{\mathrm{b}}$ & $11.97 \pm 6.874$ & $1.888 \pm 1.770$ \\
\hline$>4500 \mathrm{~m}$ & 238 & $1.576 \pm 0.960$ & $69.69 \pm 27.37^{b}$ & $6.974 \pm 3.244^{\mathrm{b}}$ & $12.05 \pm 7.111$ & $1.555 \pm 1.031^{\mathrm{a}}$ \\
\hline
\end{tabular}

Note: Compared with the control group, ${ }^{\mathrm{a}} p<0.05,{ }^{\mathrm{b}} p<0.01$.

Table 15. Test results on TT3, TT4, FT3, FT4 and TSH levels of populations exposed to different altitudes $(\bar{x} \pm s)$.

\begin{tabular}{|c|c|c|c|c|c|c|}
\hline Group & $n$ & $\mathrm{TT}_{3}(\mu \mathrm{g} / \mathrm{L})$ & $\mathrm{TT}_{4}(\mu \mathrm{g} / \mathrm{L})$ & $\mathrm{FT}_{3}(\mathrm{pmol} / \mathrm{L})$ & $\mathrm{FT}_{4}(\mathrm{pmol} / \mathrm{L})$ & TSH (mIU/L) \\
\hline Control group & 348 & $1.737 \pm 1.420$ & $60.699 \pm 25.221$ & $5.116 \pm 3.321$ & $10.725 \pm 7.180$ & $1.805 \pm 1.309$ \\
\hline$\leq 20$ months & 164 & $1.593 \pm 0.803$ & $69.667 \pm 26.833^{b}$ & $6.867 \pm 3.080^{b}$ & $10.661 \pm 5.701$ & $1.593 \pm 0.988$ \\
\hline 21 - 40 months & 279 & $1.513 \pm 0.954^{\mathrm{a}}$ & $69.684 \pm 27.127^{b}$ & $6.858 \pm 3.475^{b}$ & $12.18 \pm 7.896^{\mathrm{a}}$ & $1.698 \pm 1.596$ \\
\hline$>40$ months & 183 & $1.482 \pm 0.867^{\mathrm{a}}$ & $69.809 \pm 26.564^{\mathrm{b}}$ & $7.309 \pm 3.413^{b}$ & $11.686 \pm 7.690$ & $1.684 \pm 1.299$ \\
\hline
\end{tabular}

Note: Compared with the control group, ${ }^{\mathrm{a}} p<0.05,{ }^{\mathrm{b}} \mathrm{p}<0.01$. 


\subsection{Changes in Sex Hormones after Returning to Low Altitude}

The follicle-stimulating hormone (FSH), testosterone and estradiol $\left(E_{2}\right)$ levels of the observation group were slight lower than the control group, and the rest three were slightly higher than control, but the differences were no significant in all cases $(p>0.05)$ (Table 17). Further statistical analysis on indices that were detected as not normal (increase or decrease) showed that the detection rates for either abnormally high or abnormally low indices were not significantly different between the observation group and the control group. Correlation analysis showed that after control for age, FSH, luteinizing hormone (LH), prolactin (PRL), progesterone testosterone or estradol was not significantly correlated with altitude, residence time at high altitude, or time after returning to the plain $(p>0.05)$. This suggests that 3 years after returning to the plain, the sex hormone indices of population exposed to high altitude have returned to the level of plain population of the same age. Hypo-sexuality manifested in some who return to the plain from high altitude may not be related to sex hormone; rather, psychological and social factors may be involved.

\subsection{Changes in Free Radicals after Returning to Low Altitude}

The test results showed that the superoxide dismutase (SOD) level of the observation group was significanly higher than that of the control group, and the malondialdehyde (MDA) level of the observation group was significantly lower than that of the control group. For the rest of the four indices (ROS, GSH-PX, NOS, NO), the levels of the observation group were all higher than control, but the differences were not significant (Table 18).

Correlation analysis showed that after control for age and sex, SOD level was positively correlated with residence time at high altitude, time after returning to the plain and construction altitude; MDA level was negatively correlated with residence time at high altitude, time after returning to the plain and construction altitude; for the rest of the four indices, none was significantly correlated with any of the above high altitude factors.

Table 16. Test results on TT3, TT4, FT3, FT4 and TSH levels of populations at different times after returning to plain $(\bar{x} \pm s)$.

\begin{tabular}{ccccccc}
\hline Group & $n$ & $\mathrm{TT}_{3}(\mu \mathrm{g} / \mathrm{L})$ & $\mathrm{TT}_{4}(\mu \mathrm{g} / \mathrm{L})$ & $\left.\mathrm{FT}_{3} \mathrm{pmol} / \mathrm{L}\right)$ & $\mathrm{FT}_{4}(\mathrm{pmol} / \mathrm{L})$ & $\mathrm{TSH}(\mathrm{mIU} / \mathrm{L})$ \\
\hline Control group & 348 & $1.737 \pm 1.420$ & $60.699 \pm 25.221$ & $5.116 \pm 3.321$ & $10.725 \pm 7.180$ & $1.805 \pm 1.309$ \\
$\leq 20$ months & 96 & $1.706 \pm 1.250$ & $75.611 \pm 28.285^{\mathrm{b}}$ & $7.637 \pm 4.115^{\mathrm{b}}$ & $10.329 \pm 6.224$ & $1.489 \pm 1.029$ \\
21 - 40 months & 431 & $1.494 \pm 0.805^{\mathrm{b}}$ & $68.868 \pm 26.998^{\mathrm{b}}$ & $6.928 \pm 3.070^{\mathrm{b}}$ & $12.009 \pm 7.509^{\mathrm{a}}$ & $1.687 \pm 1.344$ \\
$>40$ months & 99 & $1.496 \pm 0.837$ & $68.191 \pm 23.983$ & $6.611 \pm 3.706^{\mathrm{b}}$ & $11.017 \pm 7.153$ & $1.702 \pm 1.693$ \\
\hline
\end{tabular}

Note: Compared with the control group, ${ }^{\mathrm{a}} p<0.05,{ }^{\mathrm{b}} p<0.01$.

Table 17. Test results on FSH, LH, PRL, P, T and E2 levels of populations exposed to high altitude after returning to plain $(\bar{x} \pm s)$.

\begin{tabular}{cccccccc}
\hline Group & $n$ & FSH $(\mathrm{IU} / \mathrm{L})$ & $\mathrm{LH}(\mathrm{IU} / \mathrm{L})$ & PRL $(\mathrm{mlU} / \mathrm{L})$ & $p(\mu \mathrm{g} / \mathrm{L})$ & $\mathrm{T}(\mu \mathrm{g} / \mathrm{L})$ & $\mathrm{E}_{2}(\mathrm{pmol} / \mathrm{L})$ \\
\hline Observation group & 626 & $4.097 \pm 3.273^{\mathrm{a}}$ & $2.644 \pm 3.164^{\mathrm{a}}$ & $231.96 \pm 219.77^{\mathrm{a}}$ & $0.892 \pm 0.883^{\mathrm{a}}$ & $2.927 \pm 1.902^{\mathrm{a}}$ & $174.68 \pm 209.80^{\mathrm{a}}$ \\
Control group & 348 & $4.384 \pm 4.101$ & $2.590 \pm 2.922$ & $211.29 \pm 181.89$ & $0.821 \pm 0.854$ & $3.002 \pm 2.547$ & $197.53 \pm 215.63$ \\
$\quad$\begin{tabular}{c}
$p$ value \\
\hline
\end{tabular} & & 0.320 & 0.831 & 0.227 & 0.318 & 0.662 & 0.188 \\
\hline
\end{tabular}

Note: Compared with the control group, ${ }^{\mathrm{a}} p<0.05,{ }^{\mathrm{b}} p<0.01$.

Table 18. Test results on ROS, SOD, MDA, GSH-PX, NOS and NO levels of populations exposed to high altitude after returning to plain $(\bar{x} \pm s)$.

\begin{tabular}{cccccccc}
\hline Group & $n$ & ROS $(\mathrm{u} / \mathrm{L})$ & SOD $(\mathrm{u} / \mathrm{gHb})$ & MDA $(\mu \mathrm{mol} / \mathrm{g})$ & GSH-PX $(\mathrm{u} / \mathrm{L})$ & NOS $(\mathrm{u} / \mathrm{ml})$ & NO $(\mu \mathrm{mol} / \mathrm{L})$ \\
\hline Observation group & 132 & $1170.4 \pm 735.2$ & $121.1 \pm 38.25^{\mathrm{a}}$ & $15.96 \pm 8.586^{\mathrm{b}}$ & $472.3 \pm 480.8$ & $21.62 \pm 9.419$ & $46.76 \pm 37.67$ \\
Control group & 178 & $1078.7 \pm 719.5$ & $105.3 \pm 42.72$ & $21.53 \pm 8.390$ & $360.9 \pm 625.8$ & $20.85 \pm 13.45$ & $41.34 \pm 29.16$ \\
\hline
\end{tabular}

Note: Compared with the control group, ${ }^{\mathrm{a}} p<0.05,{ }^{\mathrm{b}} p<0.01$. 


\subsection{Changes in the Fatty Acid Binding Protein and Succinic Dehydrogenase Levels after Returning to Low Altitude}

The fatty acid binding protein (FABP) level of the observation group was significantly higher than that of the control group $(p<0.05)$; there was no significant difference in the succinic dehydrogenase (SDH) level between the two groups (Table 19).

Correlation analysis showed that after control for age and sex, FABP level was positively correlated with high altitude exposure time and time after returning to the plain, yet not significantly correlated with the construction altitude; the SDH level was not significantly correlated with any of the high altitude factors. FABP plays an important role in regulating the transportation of longchain fatty acid; the FABP level of the observation group was significantly higher than control, and this difference did not disappear as time after returning to the plain increased.

\subsection{Changes in Indices for Neural Damages after Returning to Low Altitude}

The test results showed that there were no significant differences in the myelin basic protein (MBP), neuron specific enolase (NSE) or S-100 protein (S100) levels between the observation group and the control group (Table 20). Correlation analysis showed that after control for age and sex, MBP, NSE or S100 level was not significantly correlated with residence time at high altitude, time after returning to the plain or construction altitude, suggesting that high altitude exposure did not cause substantial damages to the nervous system.

\subsection{Changes in the Immunological Functions after Returning to Low Altitude}

There were no significant differences in the IgA, IgG, IgM or transferrin (TRF) level between the observation group and the control group (Table 21). Partial correlation analysis showed that after control for age and sex, IgA, IgG, IgM or TRF level was not significantly correlated with residence time at high altitude, time after returning to the plain or construction altitude. The immunological indices of the observed subjects were not significantly different from those of the control subjects of the same age.

\section{DISCUSSION}

With the increasing development and construction of plateau areas, more and more people are entering high altitude for various construction work. After these people
Table 19. Test results on FABP and SDH levels of populations exposed to high altitude after returning to plain $(\bar{x} \pm s)$.

\begin{tabular}{cccc}
\hline Group & $n$ & FABP $(\mu \mathrm{g} / \mathrm{L})$ & SDH $(\mathrm{U} / \mathrm{L})$ \\
\hline Observation group & 132 & $848.5 \pm 405.9^{\mathrm{a}}$ & $10.71 \pm 7.057$ \\
Control group & 178 & $705.1 \pm 348.3$ & $10.67 \pm 6.238$ \\
\hline
\end{tabular}

Note: Compared with the control group, ${ }^{\mathrm{a}} \mathrm{p}<0.05$.

Table 20. Test results on MBP, NSE and S100 levels of populations exposed to high altitude after returning to plain $(\bar{x} \pm s)$.

\begin{tabular}{ccccc}
\hline Group & $n$ & $\mathrm{MBP}(\mu \mathrm{g} / \mathrm{L})$ & $\mathrm{NSE}(\mathrm{ng} / \mathrm{mL}) \quad \mathrm{S} 100(\mathrm{ng} / \mathrm{L})$ \\
\hline Observation group & 132 & $7.984 \pm 4.842^{\mathrm{a}} 9.275 \pm 5.725^{\mathrm{a}} 430.8 \pm 304.5^{\mathrm{a}}$ \\
Control group & 178 & $7.528 \pm 4.623$ & $7.904 \pm 5.201381 .2 \pm 253.6$ \\
\hline
\end{tabular}

Note: Compared with the control group, ${ }^{a} p<0.05$.

stay in high altitude for a period of time. When they returning to the plain where they originally reside, many do not adjust well to the plain environment. Some even show different symptoms including dizziness, palpitation, hypersomnia, fatigue, chest distress, precordial dull pain, arrhythmia and decreased cognitive function. In most cases, the symptoms disappear within a month, yet for some they may last for several years; in the severe cases, these will affect the individual's ability to work. This is the so-called high altitude deadaptation. With the high rise in the number of people entering and leaving high altitude, high altitude deadaptation has become an important factor that influences the health and work ability of population that returning to the plain from high altitude.

High altitude deadaptation is customarily called "oxygen intoxication syndrome” or low altitude reaction. Studies conducted in foreign countries compared the physiological indices of mountaineers before the climb, during the climb and after returning to the plain, and evaluated factors influencing different organs and systems as well as the recovery time; it was found that indices including EPO, cellular ATP content, partial pressure of oxygen, RBC and mean corpuscular volume were all significantly changed after the mountaineers ascended to high altitude, and 1 - 2 months after returning to the plain, these indices returned to normal. Savourey et al. suggested that after people descend to the plain, the abnormal environmental stimuli were removed, thus the change would not bring danger to human life $[7,8]$. Vogel reported that when permanent high altitude natives (43 - 50 years old) descended to sea level, their stroke indices (SI) significantly increased; heart rate significantly decreased, whereas cardiac indices (CI) remained unchanged $[9,10]$. Du et al. from our country surveyed the high altitude dea- 
Table 21. Test results on IgA, IgG, IgM and TRF levels of populations exposed to high altitude after returning to plain $(\bar{x} \pm s)$.

\begin{tabular}{cccccc}
\hline Group & $\mathrm{n}$ & IgA & IgG & IgM & TRF \\
\hline Observation group & 132 & $1.463 \pm 0.191^{\mathrm{a}}$ & $9.094 \pm 1.125^{\mathrm{a}}$ & $1.075 \pm 0.212^{\mathrm{a}}$ & $2.870 \pm 0.182^{\mathrm{a}}$ \\
Control group & 178 & $1.421 \pm 0.271$ & $9.117 \pm 1.241$ & $1.081 \pm 0.232$ & $2.888 \pm 0.183$ \\
\hline
\end{tabular}

Note: Compared with the control group, ${ }^{\mathrm{a}} p<0.05$.

daptation of 590 people in Golmud area showed that $38 \%$ of these people exhibited a series of clinical symptoms including chest stress, dizziness, hypersomnia, fatigue, anorexia and abdominal distension; the appearance of these symptoms was related to the age, residence time at high altitude and labor intensity at high altitude. Studies showed that the incidence rate of high altitude deadaptation among people with older age, long residence time at high altitude tended to be higher; those conducting physical labor showed higher incidence rate that those conducting mental labor [11]. Cui et al. surveyed 626 plateau immigrants who returned to the plain and showed that the early symptoms of deadaptation mostly occurred in the nervous and digestive systems, next in the respiratory and circulatory systems; in most cases, the symptoms disappeared in about one year and the returned plateau immigrants completely adapted to local plain environment [12]. A recent survey conducted by our group studied 2000 people who returned to the plain from high altitude, and found that the incidence rate of high altitude deadaptation was as high as $78 \%-100 \%$ [13,14], far higher than that reported by previous studies; among these, $10 \%$ suffered from severe deadaptation, 30\% moderate and $60 \%$ mild.

The results of this study showed that for people who stayed at high altitude for a substantial amount of time, a period of time after returning to the plain, the functions of most their organs returned to the level before ascending to high altitude; however, the functions of some systems and organs were still at a "sub-healthy" state, especially the blood system, the circulatory system and the nervous system. We found that in most cases, it took about a year for the hematological indices of high altitude immigrants who returned to the plain to restore to a level prior to ascending to high altitude; for a minority of these people, it took 4 - 5 years or even longer to recover to the level of control plain residents [15-17]. The recovery of the function and structure of the left and right heart ventricles of high altitude immigrants after returning to the plain was relatively slow. Studies by our group have shown that population who had been subject to short-term exposure to high altitude exhibited relatively fast recovery of the function of structure of the left and right heart ventricles, which took about a month [18-20]. For population who had been exposed to high altitude for more than 5 years, after returning to the plain, it rook 2 3 years for the function and structure of the left and right ventricles to recover in most cases, and in rare cases it took 4 - 5 years or even longer [21,22]; for population who had been exposed to high altitude for more than 10 years, after returning to the plain it rook 5 or even 10 years for the function and structure of the left and right ventricles to recover in most cases. The current study showed that after returning to the plain, although the nervous system of population exposed to high altitude was not much damaged, the memory function, especially short-term memory function substantially declined. This study also found that after returning to the plain, the fatty acid metabolism of population exposed to high altitude for a relatively long period of time was affected; in particular, the FABP level significantly increased. FABP is an important protein that regulates many types of lipid signaling molecules and maintains the stability of system metabolism. It is a family of small intracellular protein molecules $(14-15 \mathrm{kD})$, which takes part in the uptake and transportation of fatty acid, regulation of lipid metabolism, signal transduction, gene transcription, and the growth and proliferation of cells, thus regulating many biochemical processes in the cell [23]. Its increase during deadaptation suggests its role in maintaining the stability of lipid metabolism after returning to the plain. In addition, after people who have been long exposed to high altitude returned to the plain, their thyroid and pancreas functions go through a readjusting process for a considerable period of time [24]; this adjustment speeds up metabolism and contributes to fast adaptation to the plain environment, yet too much of it may cause metabolic syndromes including disturbed metabolisms of sugar and lipid, and decreased insulin sensitivity [25-27]. In particular, due to the rocketing appetite after returning to the plain, body weight increases rapidly; thus without good self control, metabolic diseases may easily occur, which can become important factors that cause obesity and Cardio-cerebral-vascular diseases [28,29]; this possibility highly needs attention. Therefore, during the considerable time of read justment after people who have lived at high altitude for a long time returning to the plain, if the transition is not stable, high altitude deadaptation syndrome may occur, severely affecting life and work.

In summary, high altitude deadaptation is a clinical 
syndrome that affects the function and metabolism of different systems in the body. Although it is not lifethreatening, in severe cases it can affect normal work and life, and thus much attention needs to be paid. It should be promptly and properly treated, in order to help people descending to the plain from high altitude to safely and stably go through the deadaptation process.

\section{AUTHOR CONTRIBUTIONS}

Conceived and designed the experiments: Zhengcai Yuan, Qi-quan Zhou; Performed the experiments: Zhangcai Yuan, Yahong Zhang, Quansheng Peng; Analyzed the data: Zhengcai Yuan, Qi-quan Zhou; Contributed reagents/materials/analysis tools: Zhengcai Yuan, Qi-quan Zhou, Xuefeng Zhang, Han Luo, Ping Guo; Wrote the manuscript: Qi-quan Zhou;English translation: Enuo Science and Technology Ltd.

\section{CONFLICT OF INTEREST}

The authors declare that no conflicts of interest exist.

\section{ACKNOWLEDGEMENTS}

The authors thank the personnel from the Central hospital of China Railway First Group Co. Ltd for their assistance in this study. This work was funded by the National Science and Technology Ministry (Grant\#2009BAI85B03) and Health Subject of Chinese PLA (Grant\# 2013BJZ032).

\section{REFERENCES}

[1] Gao, Y.Q. (2005) High altitude military medicine[M]. Chongqing Press, Chongqing, 237-238.

[2] Zhang, Y.B., Wang, Y., Liu, X.L., Feng, G.F. and Zhao, D.Y. (1996) Human and high altitude. Qinghai People's Press, Xining, 97-319.

[3] Zhu, P., Li, G.X. and Gao, L.G. (1995) Analysis on deadaptation SCL-90 test results of high altitude retirees upon return to plain. Journal of High Altitude Medicine, 5, 16-18.

[4] Han, G.L. (2009) A study on the effect of high altitude hypoxia on human cognitive functions. Journal of High Altitude Medicine, 19, 15-18.

[5] Hu, F.J. (1992) A study on the deadaptation of memory functions in high altitude residents after return to plain. Journal of Qinghai Medical College, 13, 82-85.

[6] Tierney, M.C., Yao, C., Kiss, A. and McDowell, I. (2005) Neuropsychological tests accurately predict incident Alzheimer disease after 5 and 10 years. Neurology, 64, 18531859.

http://dx.doi.org/10.1212/01.WNL.0000163773.21794.0B

[7] Savourey, G., Garcia1, N., Besnard, Y., Guinet, A., Hanniquet, A.M., et al. (1996) Pre-adaptation, adaptation and deadaptation to high altitude in humans: Cardioventilatory and haematological changes. European Journal of Applied Physiology, 73, 529-535.

\section{http://dx.doi.org/10.1007/BF00357675}

[8] Risso, A., Turello, M., Biffoni, F. and Antonutto, G. (2007) Red blood cell senescence and neocytolysis in humans after high altitude acclimatization. Blood Cells, Molecules, and Diseases, 38, 83-92. http://dx.doi.org/10.1016/j.bcmd.2006.10.161

[9] Vogel, J.A., Hartley, L.H. and Cruz, J.C. (1974) Cardiac output during exercise in altitude natives at sea level and high altitude. Journal of Applied Physiology, 36, 173176.

[10] McKenzie, D.C., Goodman, L.S., Nath, C., Davidson, B., Matheson, G.O., et al. (1991) Cardiovascular adaptations in Andean natives after 6 wk of exposure to sea level. Journal of Applied Physiology, 70, 2650-2655.

[11] Zhi, M., Yu, Z.J., Liu, C.L. and Liu, K.L. (1993) A survey on the deadaptation of 590 individuals in the Geermu area. Journal of Preventive Medicine of Chinese People's Liberation Army, 11, 374-376.

[12] Cui, S.Z., Tang, S.Y., Niu, W.Z., W.Z. and Wu. Y.A. (1999) A survey on the deadaptation of 626 high altitude immigrants after return to plain-Lasting time of the symptoms. Medical Journal of National Defending Forces in Southwest China, 9, 47-49.

[13] Fan, Y., Liu, X.L., Li, X.C., Yang, C.D., Wang, L., et al. (2012) A survey on the incidence of deadaptation of stability-maintenance troop at high altitude after return to plain. Modern Preventive Medicine, 39, 1863-1865.

[14] Shi, Z.F., Zhou, Q.Q., Ma, S.D., Yan, C.J. and Xiang. L.A. (2011) survey on the deadaptation of earthquake-relieving army men upon return to plain from high altitude. Journal of Preventive Medicine of Chinese People's Liberation Army, 29, 114-115.

[15] Yuan, Z.C. (2009) Observation on hematological changes in high altitude immigrants after return to plain. Journal of Environment and Health, 26, 522-524.

[16] Yang, Y.L., Zhou, Q.Q., Shi, Z.F., Yan, C.J. and Zhu, X.Q. (2012) A preliminary observation on the changes in the hematological indices during the deadaptation of earthquake-relieving army men upon return to plain from high altitude. Medical Journal of National Defending Forces in Northwest China, 33, 117-119.

[17] Wu, Y.H., Zhou, Q.Q., Sun, Z.M., Li, X.P. and Sun Y.C. (2014) Deadaptation changes in the hematology of Han high altitude immigrants after return to plain. Journal of Chinese Practcal Diagnosis and Therapy, 3, In press.

[18] Zhou, Q.Q., Yang, S.Y., Luo, Y.J., Qi, Y.S., Yan, Z.Q., et al. (2012) A Randomly-controlled Study on the Cardiac Function at the Early Stage of Return to the Plains after Short-term Exposure to High Altitude. PLoS ONE, 7, e31097. http://dx.doi.org/10.1371/journal.pone.0031097

[19] Yang, S.Y., Feng, E.Z., Yan, Z.Q., He, W., Tian, Z.X., et al. (2010) Relationship between acute high altitude reaction and pulmonary arterial pressure in high altitude combined strong physical work in human body and its change after return to lower altitude. Chinese Journal of Lung Diseases (Electronic Edition), 3, 90-95.

[20] He, B., Wang, J., Qian, G., Hu, M., Qu, X., Wei, Z., Li, J., Chen, Y., Chen, H., Zhou, Q. and Wang, G. (2013) Anal- 
ysis of high-altitude de-acclimatization syndrome after exposure to high altitudes: a cluster-randomized controlled trial. PLoS One, 8, e62072.

http://www.ncbi.nlm.nih.gov/pubmed/23650508 http://dx.doi.org/10.1371/journal.pone.0062072

[21] Yuan, Z.C., Wang, X.L., Hou, M.Y., Lian, D. and Zhou, Q.Q. (2010) An observation on the blood pressure, ECG and cardiothoracic ratio of high altitude immigrants after return to plain. Journal of Environment and Health, 27, 987-990.

[22] Wu, Y.H., Xiao, R., Tang, S.X., Sun, Z.M., Yin, W.J., Li, X.P., Sun, Y.C. and Zhou, Q.Q. (2013) Changes of the cardiac structure and function in Han people returning to the plain for at least 3 years a fter long-term exposure to high altitude. Modern Preventive Medicine, 40, 31623165.

[23] Furuhashi, M. and Hotamisligil, G.S. (2008) Fatty acid-binding proteins: Role in metabolic diseases and potential as drug targets. Nature Reviews Drug Discovery, 7, 489-501. http://dx.doi.org/10.1038/nrd2589

[24] Yuan, Z.C., Zhang, X.F., Zhang, L., Zhang, Y.H. and Zhou Q.Q., et al. (2010) An observation on the function of thyroid and pancreatic $\beta$ cells of high altitude immigrants after return to plain. Journal of Environment and
Health, 27, 804-807.

[25] Yuan, Z.C. and Zhang, X.F. (2011) A survey on the blood lipid level of high altitude immigrants after return to plain. Journal of Environment and Health, 28, 619-621.

[26] Lei, W., Liu, K.M., Zhang, K.M. and Li, Y.L. (2005) Relations between body mass index and the biochemical indexes of blood glucose, fat and protein metabolisms. Chinese Journal of Clinical Rehabilitation, 9, 64-65.

[27] Sorrentino, M.J. (2006) Obesity, hypertension and the metabolic syndrome. Journal of Geriatric Cardiology, 13, 59-60.

[28] Panchal, S.K., Poudyal. H., Iyer-A, Nazer, R., Alam, M.A., et al. (2011) High-carbohydrate, high-fat diet-induced metabolic syndrome and cardiovascular remodeling in rats. Journal of Cardiovascular Pharmacology, 57, 611-624. http://dx.doi.org/10.1097/FJC.0b013e3181feb90a

[29] Salazar, M.R., Carbajal, H.A., Espeche, W.G., Dulbecco, C.A., Aizpurúa, M., et al. (2011) Relationships among insulin resistance, obesity, diagnosis of the metabolic syndrome and cardio-metabolic risk. Diabetes and Vascular Disease Research, 8, 109-116. http://dx.doi.org/10.1177/1479164111403170 